\title{
Prevalence and Associated Risk Factors of Visual Disturbance among Diabetic Patient in Outpatient Clinic in Elmek Nimer University Hospital 2014- Sudan
}

\author{
Mohammed Jebreldar Abuanja ${ }^{1}$, Samah Mustafa Ahmed ${ }^{2}$ \\ ${ }^{1,2}$ Faculty of Nursing Science, Shendi University, Sudan
}

\begin{abstract}
This descriptive cross-sectional community based was conducted to assess the prevalence and associated risk factors of visual disturbance among diabetic patient in outpatient clinic in Elmek nimer hospital, in the period from April - December 2014. In this study 90 diabetic patients were included. They are selected by use probability method of sampling (simple random sampling). Data was collected by two tools (Selfadministered questionnaire, snellen test chart).The present study reveal that more than two third of study group $(68.9 \%, 66.7 \%)$ were female and their age more than 45years, respectively. More than quarters of them $(28.9 \%)$ are primary school. the highly significant statistical relation had been found between the level of education and diabetes follow up ( $p$-value 0.05). The collective evidence from this study showed that (64.4\%) of study population had Type 2 of diabetes. More than two third of patients (71.1\%) their duration of diabetes between 510 years. The highly proportion (53.3\%) of study population use Oral hypoglycemic agent. In contrast to more than quarter (26.5\%) of them had hypertension. Therefore important that effort should made using the media to create diabetic awareness in rural areas with less health services and emphasize the importance of dietary program .Less than two third (61.8\%) of study population were performing eye examination by physician. Majority (71.1\%) of study population experience of visual disturbance recently. This study explains that less than quarter $(24.4 \%, 22.2 \%)$ of study population had developed retinopathy and cataract, respectively.

It has been found from this study (25.6\%) of study population had mild vision loss with eye equity 6/18 and only (13.3\%) had profound vision loss. Finally, the study recommend that, Locally educational programmes are highly needed to reduce the risk of visual impairment and blindness among diabetics and Systematic screening for diabetic retinal disease should be provided for all people with diabetes and should be screened at least annually.

Keywords: prevalence - diabetes-patient - visual disturbance
\end{abstract}

\section{Introduction}

Diabetes mellitus is a group of metabolic diseases in which defects in insulin secretion or action result in high blood sugar level (hyperglycemia), approximately 20.8 million people in the United States have diabetes mellitus, and 6.2 million of those do not know it the incidence of diabetes mellitus varies by race and ethnicity Groups. Diabetes is a serious disease that can cause complications such as blindness, kidney failure, heart attacks, and strokes. It is a leading cause of lower limb amputations with good education and self-care, patients with diabetes can prevent or delay these complications and lead full, productive lives. A major role of the nurse is helping the patient learn to care for her or himself effectively (Lindas.Williams, paulaD.hopper:2007).

Three complications of diabetes may lead to blindness. They are retinopathy, cataracts, and glaucoma. Diabetic retinopathy is characterized by alterations in the small blood vessels in the retina. An estimated $97 \%$ of insulin-taking and $80 \%$ of non insulin-taking persons who have had diabetes for $\geq 15$ years have retinopathy; approximately $40 \%$ of insulin-taking and $5 \%$ of noninsulin-taking persons have the most severe stage, proliferative diabetic retinopathy (Ronald Klein.etal.2008).

Many risk factors affect the rate at which diabetic retinopathy progresses. These risk factors include age, race, obesity, smoking, Proteinuria, depression ,dyslipidemia ,duration of Cardiovascular diseases, uncontrolled systemic hypertension, parental history of DM, rapid glycemic control before cataract surgery, eating disorders ,and poor glycemic control Although some of these risk factors cannot be controlled, many of them can be. The rate at which vision fails can be slowed with careful management and corporation between the patient and the health care team (Nina Tumosa, 2008).

Diabetic retinopathy (BDR) was diagnosed by the presence of microaneurysms, blot hemorrhages or cotton wool spots. Proliferative diabetic retinopathy (PDR) was defined as the presence of abnormal new vessels on the disc or elsewhere. Retinopathy was classified according to diabetic retinopathy study (DRS) and early treatment diabetic retinopathy study (ETDRS) . Due to limited resources and large number of patients, retinal photography was done only in patients with evidence of retinopathy (Agrawal. R .P, etal;2003) 
Early detection and treatment of sensory injuries or diseases can reduce their impact. Any disturbance in vision disrupts a person's role performance, safety, and activities of daily living (ADLs).Nurses play an important role in recognizing symptoms of visual disorders and in assisting the individual to follow treatment, prevent recurrence, and learn new adaptive skills (Bare, et al C.2003).

The Ophthalmic nurse must be thoughtful in her approach to the visually impaired person. She must use a variety of interpersonal skills to their best advantage, including: touching as appropriate to indicate presence or to show concern; introducing herself; indicating when she is leaving; and never shouting. There is a great temptation to assume that a person who is visually impaired is also hard of hearing. The Ophthalmic nurse must always bear in mind that there is an individual human being behind the eyes that are being treated, and should care for each patient as a whole, unique person. Ophthalmic nurses will also care for and manage groups of patients linked to ophthalmic sub-specialties. With any of these expanded roles, the ophthalmic nurse must always be mindful of her professional accountability ( Mary E. Shaw and Agnes Lee, 2010).

\section{Study design:}

\section{Methods and Materials}

Descriptive cross-sectional hospital based study conducted to assess the prevalence of visual disturbance and associated risk factors diabetic patient in outpatient clinic in Elmek Nimer hospital.

\subsubsection{Study area:}

The study area is Elmek Nimer university hospital at Shendi city, River Nile State, Sudan, Shendi town is located north of Khartoum, about $176 \mathrm{~km}$. and $110 \mathrm{~km}$ south to Elddamer, the capital of River Nile State, and Shendi town is lies on the eastern bank of the River Nile with a total area about $14596 \mathrm{Km} 2$. The total population of Shendi locality is estimated at about 197589 of whom 116713 live in rural areas and 80876 in urban centers, most of them are farmers. Shendi University was established in the early 1990s and stands as a landmark institution in Higher Education.

\section{Study Setting:}

This study was carried out at Elmek nimer university hospital. This hospital was established since 2002. It is the second university hospital in Sudan. The hospital provides most types of medical services (medicine, surgery, Obstetric and Gynecological, pediatric and outpatient clinics complex). Beside these there are cardiac, renal and oncology centers). In this hospital there is a big theater complex in which most type of general operations are done. In addition to these, some of special surgery (Ophthalmic and laparoscopic surgery) are also performed in this theater complex. the outpatient provide patients follow up and medical consultation for many department including(medicine, surgery, Obstetric and Gynecological, pediatric and recent ophthalmology outpatient clinics.

\subsubsection{Study population:}

The population of this study was constituted all diabetic patients available in the above setting in the time of the study and mach the criteria of the sample. The estimated number of diabetic patients about (1680) patient. Whom coming to outpatient in Elmek Nimer university hospital for follow up. Adult diabetic patient of both sexes according to the following:

\section{$\checkmark$ Inclusion criteria:}

- Age more than 30 years from both sexes.

- Diagnose since five years or more.

- The diabetic patient coming to outpatient clinic only.

$\checkmark$ Exclusion criteria:

- Patients admitted to inpatient in the hospital.

- Newly diagnosed diabetic with less than five year.

\section{Sample Size and Sampling technique: \\ - Sample Size:}

The sample size was calculated to be (90) patient. The sample was distributed proportionally to the study population follow up days and according to total population.

\section{- Sampling techniques:}

The sample was taken from all diabetic patient, they are selected by use probability method of sampling (simple random sampling). 


\subsubsection{Data collection tools:}

For this study two tools are used to collect data to achieve the objectives of the study. Data collected by the following means:-

1. Structured questionnaire.

2. Structural snellen test chart.

\section{1- Structured questionnaire:}

The questionnaire was developed by researcher based on reviewing of literature, to assess the prevalence and associated risk factors of visual disturbance among diabetic patient in outpatient clinic in Elmek nimer hospital.

\section{2-Snellen chart:}

The researcher using a Snellen box or LogMAR that all the bulbs are in working order. When testing a patient's near vision, ensure that there is an adequate light source. It is a good idea to rotate the chart round for frequent attendees to the eye outpatient unit to minimize patients memorizing the letters on the chart. (As LogMAR has a different chart for testing each eye, this reduces opportunity for remembering all of the letters.)

\section{Pilot Study:}

A pilot study carried out after the development of the study and before embarking on the actual study (data collection). It was conduct during May2014 in order to test applicability of the tools of data collection, and to estimate the time required for filling the required forms, It was carried out on ( 10 patient ) to evaluate the contents of the tools so as to find out if the items were understood by the patient.

\section{Data collection technique:}

In this study the data was collected in two phases, the first phase the questionnaire was dispensed for participants and each one of them is allowed sufficient time to fill it, all participants return questionnaire back.

The second phase regarding the visual equity the researcher was assigned a code for each one of participants to facilitate the check vision equity measurement.

\section{Ethical considerations:}

To conduct the study the permission and the approval of the directors of the hospital was taken through the Dean of the Faculty of post graduate studies. Permission was taken from hospital general manager and from the nursing headquarters (matron) and the manger of outpatient clinic. The purpose of study was explained to each one of participants. And the researcher assured them that the data collected from the questionnaire will be remaining confidential and it's not allowed for any person to identify it. Responders were informed that they could refuse to participate in the study, and withdraw from it at any time. .

\section{Statistical Design:}

The collected data was organized, and analyzed statistically using percentage, chi- square test and one way a nova test to find out the relation between variables. Using a computerized statistical package for social sciences (SPSS version 16). The results were demonstrated as tables and figures showing numbers and percentages. Significant level considered if $\mathrm{p}$ value $<0.05 \mathrm{o}$

\section{Results}

Table: (1 )The distribution of the study population according to Socio- Demographic Characteristics (age, sex, level of education, patient's job) $(n=90)$.

\begin{tabular}{|c|c|c|}
\hline age & Frequency & Percent \\
\hline $30-35$ years & 3 & $3.3 \%$ \\
\hline $36-40$ years & 6 & $6.7 \%$ \\
\hline $41-45$ years & 19 & $21.1 \%$ \\
\hline More than 45 year & 62 & $68.9 \%$ \\
\hline Total & 90 & $100 \%$ \\
\hline sex & & \\
\hline Male & 30 & $33.3 \%$ \\
\hline Female & 60 & $66.7 \%$ \\
\hline Total & 90 & $100 \%$ \\
\hline level of education & & \\
\hline Illiterate & 49 & $54.4 \%$ \\
\hline Primary & 26 & $28.9 \%$ \\
\hline High school & 14 & $15.6 \%$ \\
\hline University graduate & 1 & $1.1 \%$ \\
\hline Total & 90 & $100 \%$ \\
\hline job & & \\
\hline Employed & 25 & $27.8 \%$ \\
\hline Unemployed retired & 42 & $46.7 \%$ \\
\hline Unable to work & 23 & $25.6 \%$ \\
\hline Total & 90 & $100 \%$ \\
\hline
\end{tabular}


Prevalence and Associated Risk Factors of Visual Disturbance among Diabetic Patient in Outpatient...

Table (2). The distribution of the study population according to type of diabetes and Duration of diabetes.

\begin{tabular}{|c|c||c|}
\hline Type of diabetes & Frequency & Percent \\
\hline Type 1 & 32 & $35.6 \%$ \\
\hline Type 2 & 58 & $64.4 \%$ \\
\hline Total & 90 & $\mathbf{1 0 0 \%}$ \\
\hline Duration of diabetes & & \\
\hline $5-10$ years & 64 & $71.1 \%$ \\
\hline $11-15$ years & 12 & $13.3 \%$ \\
\hline $16-20$ years & 7 & $7.8 \%$ \\
\hline More than 20 year & 7 & $7.8 \%$ \\
\hline Total & 90 & $100 \%$ \\
\hline
\end{tabular}

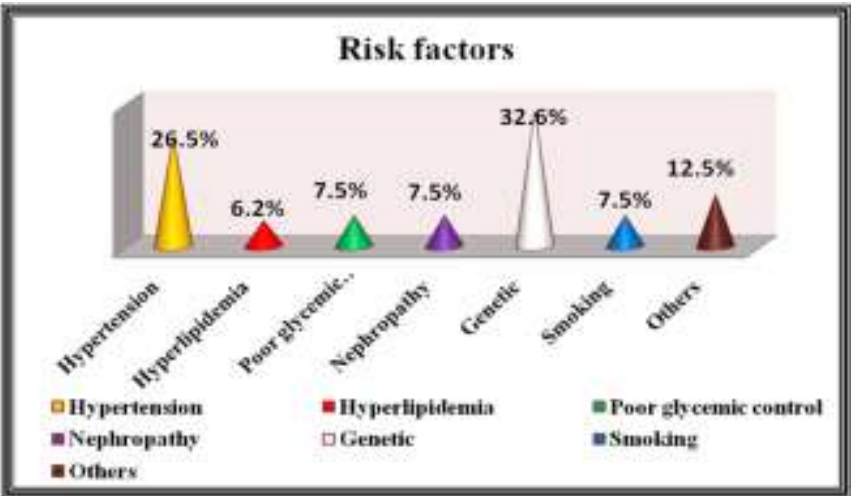

Figure (1). The risk factors among study population $(n=90)$.

Table (3). The distribution of the study population according to hyperglyce mia attact and last hyperglycemia attack.

\begin{tabular}{|c|c|c|}
\hline Hyperglycemia attack & Frequency & Percent \\
\hline Always & 10 & $11.1 \%$ \\
\hline Rarely & 56 & $62.2 \%$ \\
\hline Never & 24 & $26.7 \%$ \\
\hline Total & 90 & $100 \%$ \\
\hline Last Hyperglycemia attact & & \\
\hline Month ago & 27 & $30 \%$ \\
\hline 2-3months ago & 10 & $11.1 \%$ \\
\hline More than 4 month & 4 & $4.4 \%$ \\
\hline Not remember & 25 & $27.8 \%$ \\
\hline Never & 24 & $26.7 \%$ \\
\hline Total & 90 & $100 \%$ \\
\hline
\end{tabular}

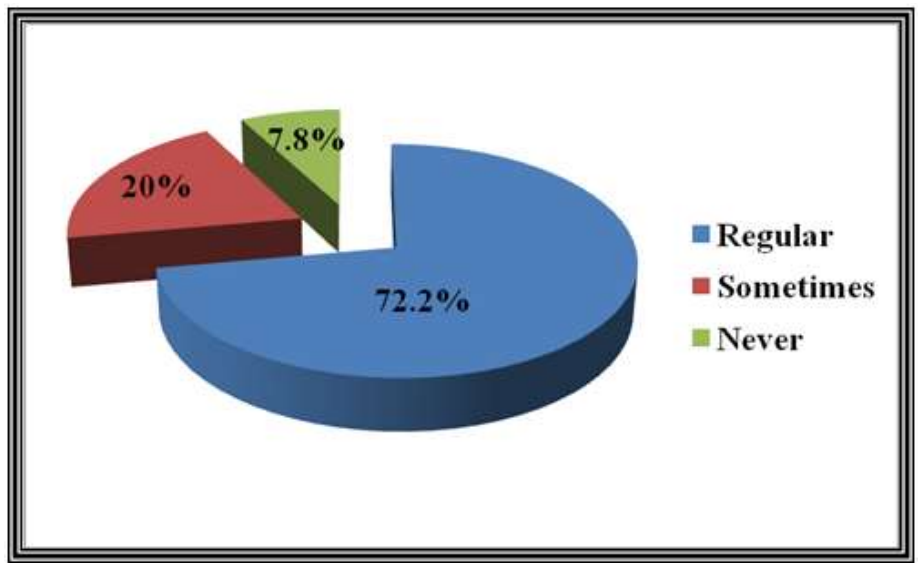

Figure (2). The Diabetes follow up among study population $(\mathrm{n}=90)$. 
Table (4). The experience of visual disturbance among study population $(n=90)$.

\begin{tabular}{|c|c|c|}
\hline Visual disturbance experience & Frequency & Percent \\
\hline Never & 26 & $28.9 \%$ \\
\hline Recently & 64 & $71.1 \%$ \\
\hline Total & $\mathbf{9 0}$ & $\mathbf{1 0 0} \%$ \\
\hline
\end{tabular}

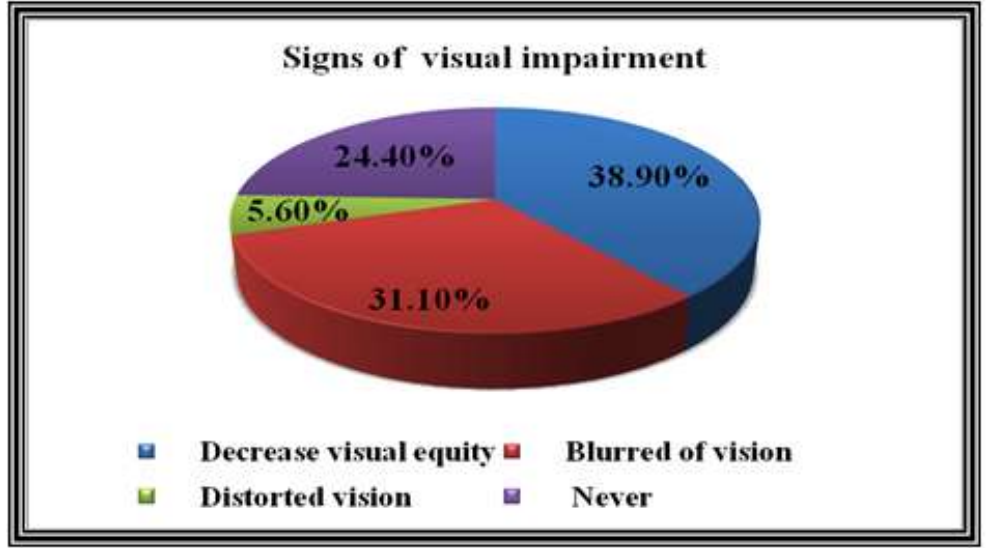

Figure (3). The Signs of visual impairment before among study population.

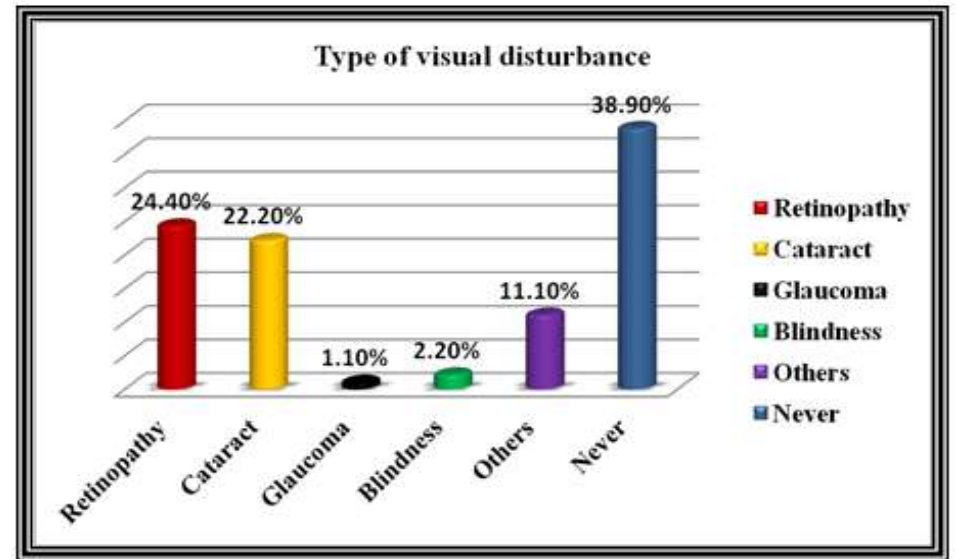

Figure (4). The distribution of the study population according to type of visual disturbance.

Table (5). The distribution of the study population according to Visual equity and range of vision loss.

\begin{tabular}{|c|c|c|c|}
\hline Visual equity & Range of vision loss & Frequency & Percent \\
\hline $6 / 9-6 / 6-6 / 4$ & Normal & 32 & $35.6 \%$ \\
\hline $6 / 18$ & Mild & 23 & $25.6 \%$ \\
\hline $6 / 24$ & Moderate & 9 & $10 \%$ \\
\hline $6 / 36$ & Sever & 14 & $15.6 \%$ \\
\hline $6 / 60$ & Profound & 12 & $13.3 \%$ \\
\hline Total & & $\mathbf{9 0}$ & $\mathbf{1 0 0} \%$ \\
\hline
\end{tabular}

Table. (6) The relation between the level of education and diabetes follow up.

\begin{tabular}{|r|r|r|r|r|r|r|}
\hline \multicolumn{2}{|c|}{} & \multicolumn{3}{|c|}{ Diabetes follow up } & \multirow{2}{*}{ Total } & \multicolumn{1}{|c|}{ P-value } \\
\cline { 3 - 6 } \cline { 3 - 6 } level of education & Regular & Sometimes & Never & \\
& Illiterate & 35 & 11 & 3 & $\mathbf{4 9}$ \\
\cline { 2 - 6 } & Primary & 19 & 3 & 4 & $\mathbf{2 6}$ \\
\cline { 2 - 6 } & High school & 10 & 4 & 0 & $\mathbf{1 4}$ & $\mathbf{0 . 0 0} * *$ \\
\cline { 2 - 6 } & University Graduate & 1 & 0 & 0 & $\mathbf{1}$ \\
\hline
\end{tabular}

* Significant at P. value $\leq 0.05$

** Highly significant at $\mathrm{p}$. value $\leq 0.001$ 
Table (7) the relation between the age and range of vision loss.

\begin{tabular}{|c|c|c|c|c|c|c|c|c|}
\hline & & \multicolumn{5}{|c|}{ Range of vision loss } & \multirow[t]{2}{*}{ Total } & P-value \\
\hline & & Normal & Mild & Moderate & Sever & Profound & & \multirow{6}{*}{$0.01 * *$} \\
\hline \multirow{4}{*}{ Age } & 30-35 years & 1 & 2 & 0 & 0 & 0 & 3 & \\
\hline & $36-40$ years & 2 & 3 & 0 & 1 & 0 & 6 & \\
\hline & $41-45$ years & 11 & 4 & 2 & 2 & 0 & 19 & \\
\hline & More than 45 & 18 & 14 & 7 & 11 & 12 & 62 & \\
\hline & Total & 32 & 23 & 9 & 14 & 12 & 90 & \\
\hline
\end{tabular}

Table (8) the relation between the Duration of diabetes and type of visual disturbance.

\begin{tabular}{|c|c|c|c|c|c|c|c|c|}
\hline & & \multicolumn{6}{|c|}{ Type of visual disturbance } & \multirow[t]{2}{*}{ Total } \\
\hline & & Retinopathy & Cataract & Glaucoma & Blindness & Others & Never & \\
\hline \multirow{4}{*}{$\begin{array}{c}\text { Duration } \\
\text { of diabetes }\end{array}$} & $5-10$ years & 15 & 12 & 0 & 1 & 5 & 31 & 64 \\
\hline & 11-15 years & 2 & 3 & 0 & 1 & 3 & 3 & 12 \\
\hline & $16-20$ years & 2 & 4 & 1 & 0 & 0 & 0 & 7 \\
\hline & More than 20 & 3 & 1 & 0 & 0 & 2 & 1 & 7 \\
\hline \multicolumn{2}{|r|}{ Total } & 22 & 20 & 1 & 2 & 10 & 35 & 90 \\
\hline \multicolumn{2}{|r|}{ P-value } & \multicolumn{7}{|r|}{$\mathbf{0 . 0 3}$} \\
\hline
\end{tabular}

\section{Discussion}

The prevalence of diabetes is increasing due to longer survival and lifestyle changes, in some countries its prevalence is reaching more than $10 \%$. After 20 years, $90 \%$ of patients with diabetes type I, and $60 \%$ of those with type II will have some form of retinopathy; of these, 5\% will require treatment to avoid irreversible blindness.

According to the World Health Organization (WHO), approximately 314 million people worldwide are visually impaired, 45 million are blind, and nearly $80 \%$ of the world's blindness can be prevented or treated. Disparities in vision health (eye disease, visual impairment, and related disability) exist among certain age, sex, socio-demographic, racial, and geographic subgroups (Who, 2010). There-fore, this descriptive, cross-sectional hospital-based study attempt to assess the prevalence of visual disturbance and associated risk factors among diabetic patients in outpatient clinic in Elmek Nimer hospital Patient in outpatient clinic in Elmek Nimer hospital. In period extend from April to December 2014.

The present study reveal that more than two third of study group $(68.9 \%, 66.7 \%)$ were female and their age more than 45years, respectively. With only $21.1 \%$ of study population their age rang 41-45 years. The elderly diabetic patient is 1.5 times more likely to develop vision loss and blindness than is an age-matched non diabetic person. Just as age is a risk factor for developing multiple chronic medical conditions, so that age a risk factor for developing multiple visual comorbidities. Indeed, cataracts, glaucoma and macular degeneration are four times more likely to cause vision loss and blindness than is diabetic retinopathy (Sinclair AJ, etal.2010).

Concerning the educational level the study revealed that less than half (54.4\%) are Illiterate. More than quarters of them $(28.9 \%)$ are primary school. the highly significant statistical relation had been found between the level of education and diabetes follow up ( $p$-value 0.05). On the other hand less than half of the patients are Unemployed retired. The employed are (27.8\%).

This mean the study population there are increase chance of developing visual impairment with illiteracy. So that they neglect their checkups and so that irreversible changes that could lead to blindness occur

The collective evidence from this study showed that $(64.4 \%)$ of study population had Type 2 of diabetes. More than third of them (35.6\%) had Type 1 of diabetes. More than two third of patients $(71.1 \%)$ their duration of diabetes between 5-10 years. While same percentage $(7.8 \%)$ of them their duration of diabetes range between 16-20 years. For that reason, the incidence and mortality of visual impairment, perhaps to be high, remarkably constant and the frequency is increasing particularly amongst Type 2 of diabetes with long duration. There was a significant statistical relation between duration and type of visual disturbance (P-value, 0.03).

The highly proportion $(53.3 \%)$ of study population use Oral hypoglycemic agent. While more than two fifth $(42.2 \%)$ of the study population use insulin. With $4.4 \%$ of study population depend on diet only. As well as more than two third $(71.1 \%)$ study group are in diabetes dietary program. Nearly third $(32.6 \%)$ of the study population had genetic predispose factor for diabetes. In contrast to more than quarter $(26.5 \%)$ of them had hypertension .while similar percentage $(7.5 \%)$ had poor glycemic control, nephropathy and smoking. Therefore important that effort should made using the media to create diabetic awareness in rural areas with less health services and emphasize the importance of dietary program and screening of risk factors as appears to be better media to reach a wider audience.

The study showed that more than three fifth $(62.2 \%)$ of study population are rarely had hypoglycemic attact. Furthermore, same percentage (26.7\%) never complain from this attach. While, less than third (30\%) of study population reveal that the last experience of hypoglycemic attact in the month ago. On other hand (27.8\%)reveal they are not remember . the finding from this research indicate that a proper follow up of all 
diabetic patient it is justifiable that hypoglycemic attack is not occur if the diabetes management are established early and they follow the screening recommendations including glucose monitoring and control.

As regarding the Diabetes follow up among patients the study displays that most of the study population (41.6\%) are on regular follow up. While less than two third (61.8\%) of study population were performing eye examination by physician. Majority $(71.1 \%)$ of study population experience of visual disturbance recently. nearly two fifth $(38.9 \%)$ of the study population reveals that they had complain from decrease visual equity before. in contrast to less than one third (31.1\%) of them complain from blurred of vision before This is good indication for services provided by medical team in outpatient clinic. This finding are compatible with those of (Veterans health institute, 2002) the eye examination should be provided by an optometrist or ophthalmologist. Retinal photographs may be done to assist with patient screening and management; however, it is not intended to replace the need for a comprehensive eye exam.

This study explains that less than quarter $(24.4 \%, 22.2 \%)$ of study population had developed retinopathy and cataract, respectively. While more than one third (28.9\%) of study population never develop this complications. on the other hand, nearly two fifth (38.9\%) of the study population reveals that they had complain from decrease visual equity before this is in contrast to less than one third (31.1\%) of them complain from blurred of vision before. this finding is constant with study done in Yemenis with diabetes which reveal that Cataract, proliferative diabetic retinopathy (PDR) and diabetic maculapathy were the main causes of visual impairment and blindness. Patients with PDR and maculapathy were significantly more likely to have visual impairment compared to patients without retinopathy(S.A. Al-Akily, 2011).

According to (World health organization, 2007) stated the prevalence of visual impairment and blindness due to diabetic retinopathy and diabetic eye complications is on the rise. Diabetic retinopathy is a priority disease in the VISION 20/20initiative for the global elimination of avoidable blindness and World Health Organization (WHO) has made prevention of visual impairment and blindness an international priority. Most diabetes-associated blindness is due to complications of diabetic retinopathy and diabetic maculapathy (WHO, 2007)

It has been found from this study (35.6\%) of study population had normal visual equity. Quarter of them (25.6\%) had mild vision loss with eye equity $6 / 18$ and only $(13.3 \%)$ had profound vision loss. (15.6\%, $10 \%$ ) of the diabetic patient had moderate to severe vision loss with eye equity more than 6/36-6/60.which reflect Screening for diabetic visual impairment in patients with diabetes mellitus has been going on in our hospital . All patients with diabetes mellitus are examined annually.

\section{Recommendation}

In the light of the results, the following recommendation can be made:

$>$ Locally educational programmers are highly needed to reduce the risk of visual impairment and blindness among diabetics.

> Systematic screening for diabetic retinal disease should be provided for all people with diabetes and should be screened at least annually.

$>$ Initiation of the Prevention of Blindness Programme in the Ministry of Health and Population should address for diabetic retinopathy and proper planning of a public health programme is crucial.

$>$ Advocates the inclusion of primary eye care as a part of PHC system in Shendi locality.

\section{References}

[1]. Bare, Brenda G., Smeltzer, Suzanne C.(2003):Brunner and Suddarth's Textbook of Medical-Surgical Nursing,10th edition, Lippincott Williams \& Wilkins, pp. 2227.

[2]. International Council of Ophthalmology , visual standards aspects and ranges of vision loss, at the 29th International Congress of Ophthalmology Sydney, Australia, April 2002

[3]. Linda.sWilliams,paulaD.hopper Understanding medical surgical nursing, Second Edition ,copyright 2007.

[4]. Mary E. Shaw and Agnes Lee, 2010. Ophthalmic Nursing, Fourth edition published by Blackwell Science Ltd 2010:9 www.wiley.com/wiley-blackwell.

[5]. Nina Tumosa. (2008) Eye Disease and the Older Diabetic.Clinics in Geriatric Medicine 24 515-527.

[6]. R P Agrawal, M Ranka, R Beniwal, S R Gothwal, G C Jain, D K Kochar, R P Kothari. (2003), Prevalence of diabetic retinopathy in type 2 diabetes in relation to risk factors: hospital based study International Journal of Diabetes in developing. Countries vol. 23.

[7]. Ronald Klein, MD, MPH, and Barbara E.K. Klein, MD, MPH, (2008).Vision Disorders in Diabetes,

[8]. S.A. Al-Akily, M.A. Bamashmus and A.A. Gunaid. Causes of visual impairment and blindness among Yemenis with diabetes: a hospital-based study Eastern Mediterranean Health Journal.Vol. 17 No. 11 • 2011.

[9]. Sinclair AJ, Bayer AJ, Girling AJ, et al. Older adults, diabetes mellitus and visual acuity:a community-based case-control study. Age Ageing 2000; 29:335-9.

[10]. World Health Organization and International Agency for the Prevention of Blindness: Diabetic Retinopathy. In: Global Initiative for the Elimination of Avoidable Blindness Action Plan 2006-2011. Geneva, World Health Organization, 2007:34-36.

[11]. World Health Organization. Vision 2020: The Right to Sight. 2010. 